\title{
The associations of body mass index, bioimpedance spectroscopy-based calf intracellular resistance, single-frequency bioimpedance analysis and physical performance of older people
}

\author{
Mikko P. Björkman ${ }^{1}$. Satu K. Jyväkorpi ${ }^{2} \cdot$ Timo E. Strandberg $^{2,3} \cdot$ Kaisu H. Pitkala ${ }^{2} \cdot$ Reijo S. Tilvis $^{1}$
}

Received: 19 March 2019 / Accepted: 2 August 2019 / Published online: 29 August 2019

(c) The Author(s) 2019

\begin{abstract}
Background Bioimpedance skeletal muscle indices (SMI) are used as a surrogate for skeletal muscle mass, but their associations with physical functioning and obesity need further evaluation.

Aims To compare the associations of body mass index (BMI), bioimpedance spectroscopy-based calf intracellular resistance (Cri-SMI), and single-frequency bioimpedance analysis (SF-SMI) indices with physical performance and the functioning of community-dwelling older people at risk of or already suffering from sarcopenia.

Methods Pre-intervention measurements of the screened subjects and the participants of the Porvoo sarcopenia trial $(N=428)$ were taken. Cri-SMI, whole-body SF-SMI, and BMI were related to hand-grip strength, walking speed, short physical performance battery (SPPB), and the physical component of the RAND-36.

Results Among the older people (aged 75-96), Cri-SMI correlated inversely with age (men $r=-0.113, p<0.001$; women $r=-0.287, p<0.001)$, but positively with SPPB $(r=0.241, p<0.001)$ and the physical component of the RAND-36 $(r=0.114$, $p=0.024)$, whereas BMI was inversely associated with SPPB $(r=-0.133, p<0.001)$ and RAND-36 $(r=-0.286, p<0.001)$. After controlling for age, gender, and comorbidity, one unit of Cri-SMI $\left(\mathrm{cm}^{2} / \Omega\right)$ was associated with a 3.3-fold probability of good physical performance ( $\mathrm{SPPB} \geq 9$ points, $\mathrm{OR}=3.28, p<0.001)$ and one unit of $\mathrm{BMI}\left(\mathrm{kg} / \mathrm{m}^{2}\right)$ decreased the respective probability $4 \%(\mathrm{OR}=0.96, p=0.065)$. Physical inactivity partly explained the negative association of BMI. When Cri-SMI and BMI were controlled for, a $1 \%$ difference in Cri-SMI was associated with a $0.7 \%(p<0.001)$ higher probability of good performance, the respective figure being $-2.2 \%(p=0.004)$ for BMI. The associations of SF-SMI with physical functioning indices were insignificant.

Conclusions Independent of each other, Cri-SMI was positively and BMI was inversely associated with the physical performance and functioning of community-dwelling older people who were at risk of or already suffering from sarcopenia. We found no association between SF-SMI and physical functioning.
\end{abstract}

Keywords Bioelectrical impedance $\cdot$ Intracellular resistance $\cdot$ Muscle strength $\cdot$ Physical performance $\cdot$ Sarcopenia

\section{Introduction}

Mikko P. Björkman

bjorkmik@gmail.com

1 Geriatric Unit, Department of Internal Medicine, Institute of Clinical Medicine, University of Helsinki, POB 20, 00014 Helsinki, Finland

2 Department of General Practice and Primary Health Care, University of Helsinki, Helsinki, Finland

3 Center for Life Course Health Research, University of Oulu, Oulu, Finland
Age-related muscle loss, i.e., sarcopenia is a significant contributor to declining physical functioning and reduced quality of life among older people [1,2]. According to a recent consensus definition, sarcopenia is determined by muscle strength, muscle quality and quantity, and physical performance [3]. This creates a need to measure the muscle mass of heterogeneous older populations in a wide range of clinical settings. Different body imaging techniques, such as computed tomography, magnetic resonance imaging or dualenergy X-ray absorptiometry (DEXA), have been recommended for the measurement of muscle mass [3]. However, 
these imaging techniques require a visit to a laboratory or a hospital, which may present difficulties in availability and be problematic for some older sarcopenic people with disabilities. Bioimpedance analysis (BIA) is a portable alternative for assessing body composition $[4,5]$ and is thus suitable for primary health care settings, including home visits. However, the accuracy of algorithm-based single-frequency BIA (SF-BIA) in the assessment of the muscle mass of some older population, in particular, has been questioned [6-8]. SF-BIA estimates of muscle mass are based on algorithms that are often derived from relatively healthy subjects, and so may be a source of inaccuracy among older multimorbid and disabled people. Furthermore, it has been suggested that the excess extracellular water in muscles may mask actual muscle atrophy during aging $[9,10]$. This extracellular water compartment may result in the overestimation of actual muscle mass when using SF-BIA and imaging techniques.

Bioimpedance spectroscopy (BIS) offers an alternative method for investigating muscle biology [6]. It uses hundreds of frequencies within a wide range, allowing the calculation of intracellular resistance (Ri), a measure that does not require participant characteristic data or population-based algorithms. $\mathrm{Ri}$ is closely related to the intracellular water (ICW) compartment and may be considered a surrogate for skeletal muscle cell mass, as fat and bone cells have a low content of intracellular water [6, 10]. Recent studies by Yamada et al. have underscored the value of BIS as a measure of muscle function and for providing information on skeletal muscle biology [11].

Changes in segmental calf intracellular skeletal muscle index (Cri-SMI) have shown to be associated with mobility decline among typical nursing-home residents [12]. We investigated the associations of BMI and two bioelectrical impedance skeletal muscle indices with the physical performance of community-dwelling older people who were at risk of or already suffering from sarcopenia. Our second aim was to evaluate the interplay of muscle mass and BMI as associates of the physical performance and functioning of old people.

\section{Methods}

This cross-sectional study is based on the baseline screening data of the Porvoo sarcopenia and Nutrition trial (ACTRN12612001253897). The trial procedures have been published elsewhere [13]. We approached the population aged $75+$ living in Porvoo, Finland $(N=3275)$ by a postal questionnaire (response rate 60.5\%) and the research group further examined the individuals at risk of sarcopenia (limitations in daily living activities, sedentary lifestyle, falls, exhaustion, old age, low body mass index (BMI)). The key exclusion criteria were not living at home, not being able to walk indoors independently (canes and walkers were allowed), and not being able to cooperate with bioimpedance and hand-grip strength measurements. We also excluded patients with cardiac pacemakers and severe skin lesions in bioimpedance electrode placement sites. The study protocol was approved by the ethics committee for internal medicine of the hospital district of Helsinki and Uusimaa. We obtained informed consent from each patient or their next of kin. Participants signed an informed consent form before beginning any trial procedures. In the case of participants' cognitive decline (Mini-mental state sxamination (MMSE) < 19) [14] or poor judgment ability, we invited a proxy to give consent in addition to the participant's consent.

We collected the demographic data and medical history via the postal questionnaire. The questionnaires included the RAND-36 physical functioning scale $[15,16]$. Patients who reported being able to walk less than $1 \mathrm{~km}$ per day on average or exercising regularly for less than $1 \mathrm{~h}$ per week were classified as physical inactive. Morbidity was assessed using the Charlson comorbidity index [17] and muscle endurance by the 2-min step test [18]. We also calculated BMI.

The participants were examined at a day clinic or during a home visit. Physical performance was assessed by the short physical performance battery (SPPB) [19], which includes a three-part balance test, habitual gait speed, and a chair stand test. Each category of SPPB is scored from 0 to 4 , so the total score ranges from 0 to 12 , with 0 indicating poorest and 12 indicating best performance. Muscle strength was assessed by a hand-grip dynamometer (JAMAR dynamometer, Saehan Corp., Masan, Korea). We recorded the mean maximum strength of both hands, as well as 4-m course habitual gait speed as a part of SPPB with a cut-off point $<0.8 \mathrm{~m} / \mathrm{s}$. We evaluated cognitive functioning using the mini-mental state examination (MMSE) [14], with a score ranging from 0 (poorest) to 30 (best).

We preformed bioimpedance spectroscopy by a singlechannel, tetra-polar device (SFB7, ImpediMed Ltd., Eight Miles Plains, Queensland, Australia) that scans 256 frequencies between 4 and $1000 \mathrm{kHz}$. The values were recorded without further software processing. The Cri-SMI was calculated from the BIS data of the calf measurements as follows: Cri-SMI $=$ electrode distance $2 / \mathrm{Ri}_{\text {calf }}\left(\mathrm{cm}^{2} / \Omega\right)$, using the means of both calves. Finally, the whole-body single-frequency skeletal muscle index (SF-SMI) was calculated from the whole-body skeletal muscle mass (SMM), and assessed according to Janssen et al. [5]. We then transformed this into a skeletal muscle index as follows: $\mathrm{SF}-\mathrm{SMI}=\mathrm{SMM} /$ height $^{2}$.

We used SPSS software (IBM Corp. Released 2012. IBM SPSS Statistics for Windows, Version 21.0. Armonk, NY: IBM Corp.) for the statistical analyses. Continuous variables with normal distribution were expressed by means of standard deviations (SD). For the variables with normal distribution, statistical comparisons between the groups were made 
using Student's $t$ test and for those with skewed distribution the Mann-Whitney $U$ test. We used the Chi-square test to examine the relationship between the two categorical variables and used Fisher's exact test when appropriate. Pearson's correlation coefficient was used to describe the bivariate correlations between the normally distributed variables and Spearman's rho for the variables with a skewed distribution. Logistic regression models were created to calculate the unadjusted and adjusted odds ratios and $95 \%$ confidence intervals. $p$ values below 0.050 were considered statistically significant.

\section{Results}

The participants $(N=428)$ were old ( 83.4 years); women outnumbered men (285 vs 143); and most (56\%) of them lived alone. They used a mean of 5.4 prescribed regular medications. The mean SPPB score was 8.2, and 54.8\% of the participants scored at least 9 points. The men had higher Charlson comorbidity indices (Table 1), larger muscle mass indices, and stronger hand-grip strength than the women. The men also tended to have better physical functioning (RAND-36) (Table 1).

We first investigated the relationship of muscle mass measures with age, BMI, and physical functioning. Cri-SMI correlated inversely with age among both the men and the women, whereas SF-SMI did not (Fig. 1). BMI correlated positively with Cri-SMI and SF-SMI, but inversely with physical performance and functioning indices (Table 2). Controlled-for age and gender Cri-SMIs were associated with good physical performance and functioning including walking speed, whereas the respective figures were

Table 1 Selected baseline characteristics (SD) of participants by gender

\begin{tabular}{lccc}
\hline Variable & Women $(N=285)$ & Men $(N=143)$ & $p$ value \\
\hline Age, years & $83.4(4.7)$ & $83.5(4.3)$ & 0.87 \\
$\begin{array}{l}\text { Charlson Comor- } \\
\quad \text { bidity Index }(\mathrm{CCI})\end{array}$ & $2.0(1.7)$ & $2.7(2.3)$ & $<0.001$ \\
MMSE & & & \\
BMI, kg/m ${ }^{2}$ & $25.9(3.2)$ & $25.2(3.9)$ & 0.059 \\
SPPB $(0-12)$ & $8.3(3.0)$ & $26.8(4.0)$ & 0.25 \\
RAND-SF $(0-100)$ & $48.4(26.7)$ & $5.2(3.0)$ & 0.80 \\
2-min walking, m & $76.3(24.3)$ & $79.0(26.6)$ & 0.30 \\
Grip strength, kg & $17.6(4.5)$ & $28.9(7.0)$ & $<0.001$ \\
SF-SMI, kg/m ${ }^{2}$ & $6.9(1.0)$ & $9.7(1.2)$ & $<0.001$ \\
Cri-SMI, cm ${ }^{2} / \Omega$ & $1.4(0.4)$ & $1.7(0.5)$ & $<0.001$ \\
\hline
\end{tabular}

$R A N D-S F$ physical functioning scale of RAND-36, MMSE minimental state examination, $B M I$ body mass index, $S F-S M I$ single-frequency skeletal muscle index, Cri-SMI segmental calf intracellular resistance skeletal muscle index insignificant for SF-SMI. We found significant, although rather weak, correlations between grip strength and BMI, muscle mass indices and physical functioning scores.

When the study population was grouped by CRi-SMI cutoff points, the individuals with low values were characterized by older age, lower BMI, weaker hand-grip strength, physical inactivity, and lower physical performance and functioning scores (Table 3). The differences were similar among both the men and the women. Closer analysis showed that low Cri-SMI was negatively associated $(p=0.002)$ with SPPB quartiles among both the men and the women. Again, we found no significant association for SF-SMI $(p=0.778)$.

Finally, the opposite relationships of BMI and Cri-SMI to physical functioning scores prompted us to test the nature of these associations in logistic regression analyses (Table 4). After controlling for age and gender, one unit of Cri-SMI was associated with a 3.3-fold probability that SPPB was at least 9 points, whereas one unit of BMI decreased the respective probability by $4 \%(\mathrm{OR}=0.96)$. Further controlling for comorbidity and physical inactivity did not substantially weaken these associations. However, physical inactivity partly explained the negative association with BMI. The odds ratios of both Cri-SMI (OR=4.4) and BMI (OR=0.92) became even stronger when controlled for each other. Due to the large differences in the scales of Cri-SMI and BMI, we used their percentage values (mean value $=100 \%$ ) for comparisons. When Cri-SMI and BMI were controlled for age, gender, comorbidity, physical activity, and for each other, a $1 \%$ difference in Cri-SMI was associated with a $0.7 \%$ $(p<0.001)$ increase in the probability of good performance, the respective figure being $-2.2 \%(p=0.004)$ for BMI. The respective associations of SF-SMI with physical functioning indices were insignificant. Finally, when patients were classified according to BMI quartiles, the associations of CriSMI with good performance were strongest in the persons with low BMI while those of BMI were inconsistent (Fig. 2).

\section{Discussion}

This cross-sectional study shows that Cri-SMI is significantly associated with good physical functioning, whereas BMI is related to poor physical functioning among community-dwelling older people. We found no association between SF-SMI and physical functioning. Our results also demonstrate that the relationships between BMI, bioimpedance skeletal muscle indices, and physical functioning scores are rather linear and the associations are "dose-dependent." Accordingly, the results are not affected by the cut-off points selected for test variables. Our data also shed new light on the interplay between age, muscle mass, physical activity, and obesity among older people. Cri-SMI and BMI were both independent associates of physical performance. 
Panel A

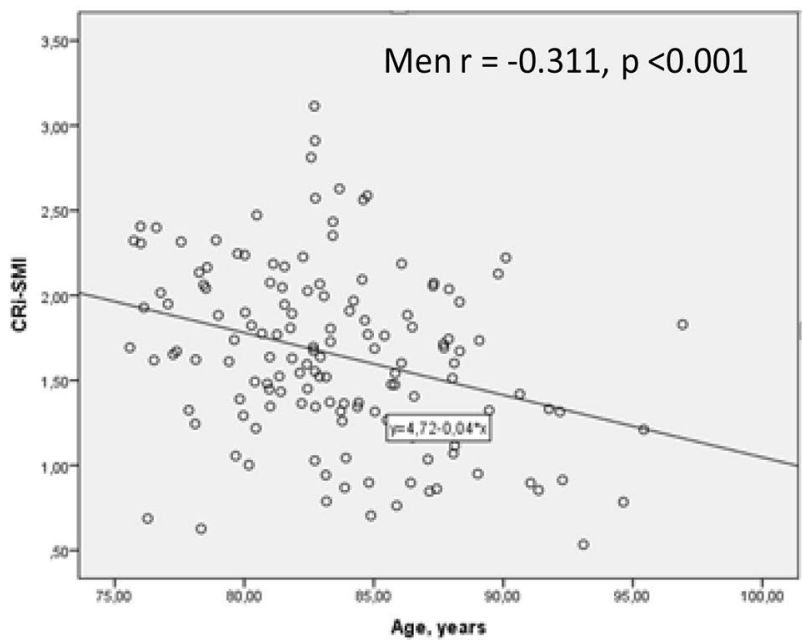

Panel C

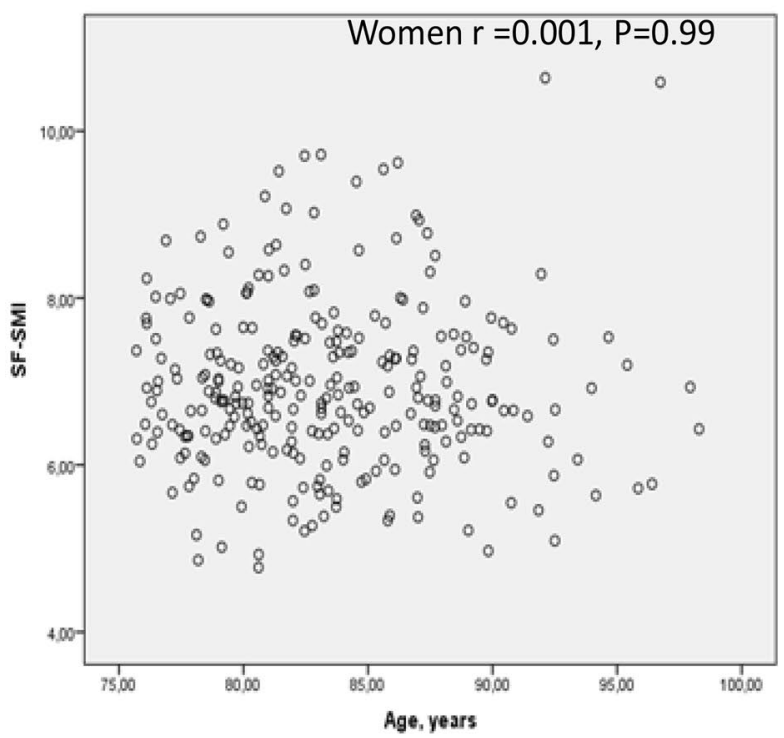

Panel B

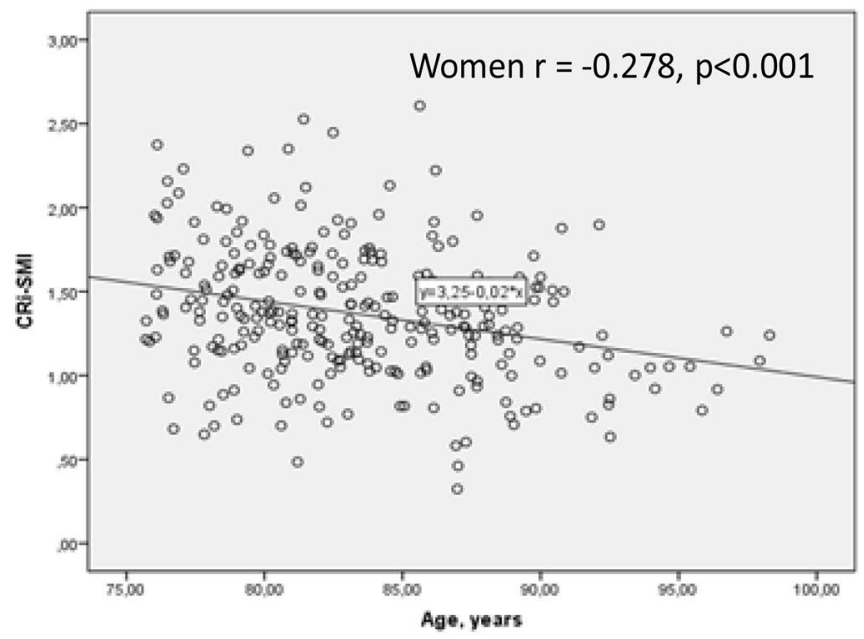

Panel D

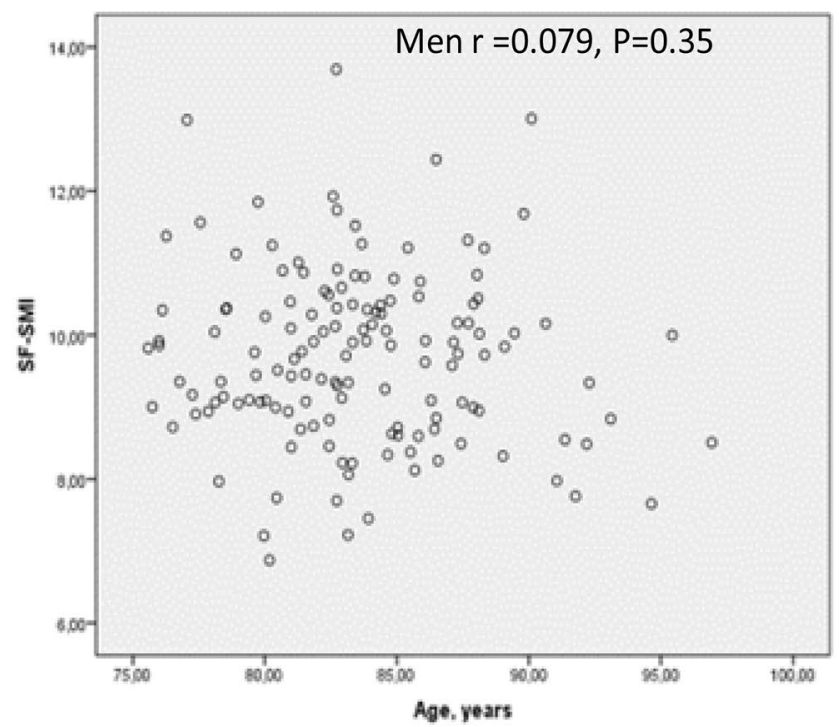

Fig. 1 Correlations of age with Cri-SMI and SF-SMI among men and women

Table 2 Age- and genderadjusted intercorrelations $(p$ values) of body mass index, bioimpedance muscle indices, and physical functioning $(N=428)$

\begin{tabular}{lccccccc}
\hline & BMI & SF-SMI & Cri-SMI & RAND-36 & SPPB & Walking speed & Grip strength \\
\hline BMI & 1 & $<0.001$ & $<0.001$ & $<0.001$ & 0.008 & $<0.001$ & 0.008 \\
SF-SMI & 0.573 & 1 & $<0.001$ & 0.029 & 0.240 & 0.105 & $<0.001$ \\
CRi-SMI & 0.346 & 0.542 & 1 & 0.024 & $<0.001$ & 0.005 & $<0.001$ \\
RAND-36 & -0.286 & -0.109 & 0.114 & 1 & $<0.001$ & $<0.001$ & $<0.001$ \\
SPPB & -0.133 & -0.059 & 0.241 & 0.580 & 1 & $<0.001$ & $<0.001$ \\
Walking speed & -0.181 & -0.082 & 0.141 & 0.505 & 0.505 & 1 & 0.004 \\
Grip strength & 0.133 & 0.197 & 0.299 & 0.191 & 0.249 & 0.144 & 1 \\
\hline
\end{tabular}

$P$ values are in italics

$R A N D-S F$ physical functioning scale of RAND-36, MMSE mini-mental state examination, $B M I$ body mass index, $S F-S M I$ single-frequency skeletal muscle index, Cri-SMI segmental calf intracellular resistance skeletal muscle index 
Table 3 Characteristics of community-dwelling older people at risk of sarcopenia by calf intracellular resistance skeletal muscle index (CriSMI)

\begin{tabular}{|c|c|c|c|c|c|c|c|c|c|}
\hline & \multicolumn{3}{|c|}{ Women (Cri-SMI cut-off point 1.50 ) } & \multicolumn{3}{|c|}{ Men (Cri-SMI cut-off point 2.06) } & \multicolumn{3}{|c|}{ Both (Gender-specific cut-off points) } \\
\hline & $\begin{array}{l}\text { Normal Cri- } \\
\text { SMI }\end{array}$ & Low Cri-SMI & $p$ value & $\begin{array}{l}\text { Normal Cri- } \\
\text { SMI }\end{array}$ & Low Cri-SMI & $p$ value & $\begin{array}{l}\text { Normal Cri- } \\
\text { SMI }\end{array}$ & Low Cri-SMI & $p$ value \\
\hline Number & 96 & 187 & & 31 & 111 & & 127 & 298 & \\
\hline & & & & & & & 75.6 & 62.8 & 0.010 \\
\hline $\begin{array}{l}\text { Age. years } \\
\quad( \pm \text { SD })\end{array}$ & $82.0 \pm 4.0$ & $84.1 \pm 5.0$ & $<0.001$ & $81.7 \pm 3.7$ & $84.0 \pm 4.4$ & 0.009 & $81.9 \pm 3.9$ & $84.1 \pm 4.8$ & $<0.001$ \\
\hline $\begin{array}{l}\text { Charlson } \\
\text { comorbidity } \\
\text { index (range) }\end{array}$ & $1.0(1.0-2.0)$ & $2.0(1.0-3.0)$ & 0.288 & $2.0(1.0-4.0)$ & $\begin{array}{l}2.0 \text { (1.0 to } \\
-4.0)\end{array}$ & 0.153 & $2(1-3)$ & $2(1-3)$ & 0.700 \\
\hline $\begin{array}{l}\text { Sedentary } \\
\quad \text { lifestyle (\%) }\end{array}$ & 32.3 & 50.3 & 0.004 & 26.7 & 33.0 & 0.507 & 31 & 43.8 & 0.014 \\
\hline $\begin{array}{l}\text { Limitations } \\
\text { walking } \\
\text { indoors }(\%)\end{array}$ & 12.5 & 21.0 & 0.080 & 19.4 & 22.9 & 0.672 & 14.2 & 21.7 & 0.073 \\
\hline $\begin{array}{l}\text { At least one } \\
\text { fall in past } \\
12 \text { months } \\
(\%)\end{array}$ & 32.6 & 36.3 & 0.543 & 46.7 & 45.4 & 0.900 & 36.0 & 39.7 & 0.476 \\
\hline $\begin{array}{l}\text { Physical func- } \\
\text { tion scale of } \\
\text { RAND-36 } \\
\text { mean points } \\
( \pm \text { SD })\end{array}$ & $54.3 \pm 24.3$ & $45.7 \pm 27.3$ & 0.011 & $55.3 \pm 27.9$ & $54.3 \pm 30.7$ & 0.865 & $55(35-75)$ & $50(25-75)$ & 0.061 \\
\hline $\begin{array}{l}\text { Short physical } \\
\text { performance } \\
\text { battery } \\
\text { (range) }\end{array}$ & $10(8-11)$ & $8(6-11)$ & 0.001 & $10(8-12)$ & $8(6-10)$ & 0.017 & $10(8-11)$ & $8(6-10)$ & $<0.001$ \\
\hline $\begin{array}{l}\text { Habitual gait } \\
\text { speed m/s } \\
( \pm \mathrm{SD})\end{array}$ & $0.95 \pm 0.28$ & $0.84 \pm 0.33$ & 0.004 & $0.93 \pm 0.30$ & $0.89 \pm 0.32$ & 0.557 & $0.95 \pm 0.28$ & $0.86 \pm 0.33$ & 0.008 \\
\hline $\begin{array}{l}\text { Walking aid } \\
\text { in gait speed } \\
\text { test }(\%)\end{array}$ & 1.0 & 4.3 & 0.281 & 0.0 & 3.6 & 0.284 & 0.79 & 4.0 & 0.120 \\
\hline $\begin{array}{l}\text { Grip strength } \\
\mathrm{kg}( \pm \mathrm{SD})\end{array}$ & $19.2 \pm 4.1$ & $16.6 \pm 4.3$ & $<0.001$ & $30.5 \pm 7.1$ & $27.1 \pm 6.9$ & 0.017 & $20.5(17.5-25)$ & $19.5(16-24.5)$ & 0.034 \\
\hline $\begin{array}{l}\text { Mini-mental } \\
\text { state } \\
\text { examination } \\
\text { (range) }\end{array}$ & $27(25-28)$ & $26(24-28)$ & 0.379 & $27(24-28)$ & $26(23-28)$ & 0.363 & $27(25-28)$ & $26(24-28)$ & 0.166 \\
\hline $\begin{array}{l}\text { Body mass } \\
\text { index. } \mathrm{kg} / \mathrm{m}^{2} \\
( \pm \mathrm{SD})\end{array}$ & $29.3 \pm 4.9$ & $26.4 \pm 4.7$ & $<0.001$ & $28.5 \pm 3.8$ & $26.3 \pm 3.9$ & 0.006 & $29.1 \pm 4.6$ & $26.4 \pm 4.4$ & $<0.001$ \\
\hline $\begin{array}{c}\text { SF-SMI }{ }^{\mathrm{a}} \cdot \mathrm{kg} / \\
\mathrm{m}^{2}( \pm \mathrm{SD})\end{array}$ & $7.6 \pm 0.9$ & $6.6 \pm 0.9$ & $<0.001$ & $10.5 \pm 1.3$ & $9.5 \pm 1.1$ & $<0.001$ & $7.8(7.1-9.3)$ & $7.3(6.4-9.0)$ & $<0.001$ \\
\hline
\end{tabular}

Means \pm standard deviations or medians with first and fourth quartile cut-off points or percentages

$S D$ standard deviation, $S F-S M I^{a}$ single frequency bioimpedance analysis

${ }^{a}$ Whole-body single-frequency skeletal muscle index

These observations support our previous longitudinal nursing-home study, which showed an association between Cri-SMI change, mobility decline, and need of help [12]. The results are also in good accordance with the data of the recent Kyoto-Kameoka Study, in which thigh BIS was a strong predictor of knee extension strength and gait speed was independent of age, sex, body mass index, and muscle mass among community-dwelling people aged between 65 and 90 [20]. 
Table 4 Associations of Cri-SMI and BMI with good physical performance $(\mathrm{SPPB} \geq 9)$

\begin{tabular}{|c|c|c|c|c|c|c|c|c|}
\hline \multicolumn{4}{|l|}{ Cri-SMI } & \multicolumn{5}{|l|}{ BMI } \\
\hline Unit & OR & $95 \%$ CIs & $p$ value & Unit & & OR & $95 \%$ CIs & $p$ value \\
\hline \multicolumn{9}{|c|}{ Unadjusted } \\
\hline $\mathrm{cm}^{2} / \Omega$ & 3.64 & $2.25-5.89$ & $<0.001$ & $\mathrm{~kg} / \mathrm{m}^{2}$ & 0.95 & & $0.91-0.99$ & 0.012 \\
\hline$\%$ & 1.006 & $1.004-1.008$ & $<0.001$ & $\%$ & 0.987 & & $0.98-1.00$ & 0.026 \\
\hline \multicolumn{9}{|c|}{ Adjusted for age and gender } \\
\hline $\mathrm{cm}^{2} / \Omega$ & 3.38 & $1.99-5.73$ & $<0.001$ & $\mathrm{~kg} / \mathrm{m}^{2}$ & 0.96 & & $0.91-0.99$ & 0.039 \\
\hline$\%$ & 1.006 & $1.003-1.008$ & $<0.001$ & $\%$ & 0.987 & & $0.77-1.00$ & 0.039 \\
\hline \multicolumn{9}{|c|}{ Adjusted for age, gender, and comorbidity } \\
\hline $\mathrm{cm}^{2} / \Omega$ & 3.28 & $1.92-5.60$ & $<0.001$ & $\mathrm{~kg} / \mathrm{m}^{2}$ & 0.96 & & $0.91-0.99$ & 0.065 \\
\hline$\%$ & 1.005 & $1.003-1.008$ & $<0.001$ & $\%$ & 0.989 & & $0.98-1.00$ & 0.065 \\
\hline \multicolumn{9}{|c|}{ Adjusted for age, gender, comorbidity, and physical inactivity } \\
\hline $\mathrm{cm}^{2} / \Omega$ & 3.17 & $1.80-5.51$ & $<0.001$ & $\mathrm{~kg} / \mathrm{m}^{2}$ & 0.97 & & $0.93-1.02$ & 0.198 \\
\hline$\%$ & 1.005 & $1.003-1.008$ & $<0.001$ & $\%$ & 0.992 & & $0.98-1.00$ & 0.198 \\
\hline \multicolumn{4}{|c|}{$\begin{array}{l}\text { Adjusted for age, gender, comorbidity, physical } \\
\text { inactivity, and BMI }\end{array}$} & \multicolumn{5}{|c|}{$\begin{array}{l}\text { Adjusted for age, gender, comorbidity, physical } \\
\text { inactivity, and Cri-SMI }\end{array}$} \\
\hline $\mathrm{cm}^{2} / \Omega$ & 4.42 & $2.39-8.22$ & $<0.001$ & $\mathrm{~kg} / \mathrm{m}^{2}$ & 0.92 & & $0.87-0.97$ & 0.004 \\
\hline$\%$ & 1.007 & $1.004-1.010$ & $<0.001$ & $\%$ & 0.98 & & $0.96-0.99$ & 0.004 \\
\hline
\end{tabular}

$B M I$ body mass index, Cri-SMI segmental calf intracellular resistance skeletal muscle index

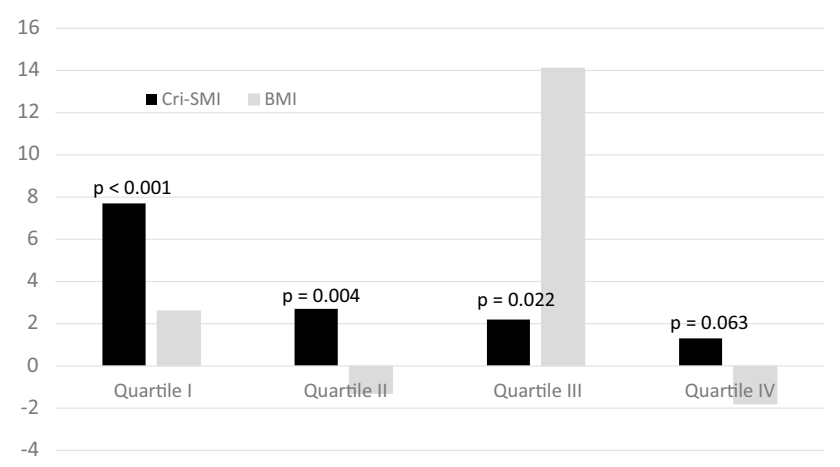

Fig. 2 Associations of Cri-SMI and BMI by BMI quartiles with good physical performance (SPPB $>9$ ). Quartile cut points: 23.95, 26.58, and $29.73 \mathrm{~kg} / \mathrm{m}^{2}$

The results provide a plausible explanation for the difference between the associations of Cri-SMI and SF-SMI. The relatively strong correlation between BMI and SF-SMI $(r=0.573, p<0.001)$ suggests that the possible positive relationship between SF-SMI and physical functioning is effectively masked by BMI having a negative influence. It is also important to note that Cri-SMI is a direct measurement, whereas SF-SMI is calculated using both height and weight. This may hamper the value of SF-SMI in the evaluation of the interplay between muscle mass and obesity.

Muscle atrophy during aging decreases the intracellular compartment of the muscle, but the extracellular fluid is maintained, resulting in an increase in the proportion of nonfunctional muscle volume [20]. This may mask age-related muscle loss. The use of intracellular resistance may diminish the confounding effect of extracellular fluid in muscle tissue. This could explain the lack of association between SF-SMI and physical performance. It should be noted that SPPB mainly measures the physical performance of the lower limbs (gait speed, chair stand, and balance). SF-SMI utilized whole-body bioimpedance measurements, whereas CriSMI was calculated from calf data, which may strengthen its association with lower limb performance-based SPPB. We did not find any significant new gender differences that should be taken into account when interpreting bioimpedance data (data not shown).

The main weakness of this study is its lack of confirmatory skeletal muscle measurements (dual X-ray absorptiometry, etc.). Its strengths are the good representatives of the population sample. Home visits were offered to ensure the participation of true geriatric patients. We used wellvalidated tools to assess physical performance. Clinically important confounders were recorded, and their influences were tested in multiple ways. Finally, to the best of our knowledge, this is the second and largest study to investigate the role of Cri-SMI in the physical performance of community-dwelling older people.

\section{Conclusions}

This study shows that Cri-SMI is associated positively and BMI inversely with the physical functioning of communitydwelling older people at risk of sarcopenia. Whole-body SFSMI correlated with BMI, but not with physical functioning scores. 
Acknowledgements Open access funding provided byUniversity of Helsinki including Helsinki University Central Hospital. This study was funded by the University of Helsinki, Konung Gustav V:s och Drottning Victorias Frimurarestiftelse, the Yrjö Jahnsson Foundation, and Valio Ltd. We greatly appreciate the cooperation of the Porvoo municipal health care services.

\section{Compliance with ethical standards}

Conflict of interest MPB reports professional cooperation including lecturing fees from Valio Ltd, Nestle Health Science Ltd. and Nutricia Medical Ltd., Dr. TES reports having various educational and consultative cooperation with several companies, including Nutricia, Abbott, Amgen, Merck, Pfizer, Novartis, and Novo-Nordisk; a minor amount of stock in Orion Pharma; and is a board member and former president of executive board of European Union Geriatric Medicine Society which has cooperation also with the nutrition industry. SKJ, KHP and RS have no competing interests.

Ethical standards The study protocol was approved by the ethics committee for internal medicine of hospital district of Helsinki and Uusimaa. The study was performed in accordance with the 1964 Declaration of Helsinki and its later amendments.

Informed consent Informed consent was obtained from each patient, or from their next of kin if necessary.

Open Access This article is distributed under the terms of the Creative Commons Attribution 4.0 International License (http://creativeco mmons.org/licenses/by/4.0/), which permits unrestricted use, distribution, and reproduction in any medium, provided you give appropriate credit to the original author(s) and the source, provide a link to the Creative Commons license, and indicate if changes were made.

\section{References}

1. Rizzoli R, Reginster JY, Arnal JF et al (2013) Quality of life in sarcopenia and frailty. Calcif Tissue Int 93:101-120

2. Shaw SC, Dennison EM, Cooper C (2017) Epidemiology of sarcopenia: determinants throughout the lifecourse. Calcif Tissue Int 101:229-247. https://doi.org/10.1007/s00223-017-0277-0

3. Cruz-Jentoft AJ, Bahat G, Bauer J et al (2019) Writing Group for the European Working Group on Sarcopenia in Older People 2 (EWGSOP2), and the extended group for EWGSOP2. Sarcopenia: revised European consensus on definition and diagnosis. Age Ageing 48:16-31. https://doi.org/10.1093/ageing/afy 169

4. Nuñez C, Gallagher D, Grammes J et al (1999) Bioimpedance analysis: potential for measuring lower limb skeletal muscle mass. JPEN J Parenter Enteral Nutr 23:96-103

5. Janssen I, Heymsfield SB, Baumgartner RN et al (2000) Estimation of skeletal muscle mass by bioelectrical impedance analysis. J Appl Physiol 89:465-471

6. Yamada Y, Watanabe Y, Ikenaga M et al (2013) Comparison of single- or multifrequency bioelectrical impedance analysis and spectroscopy for assessment of appendicular skeletal muscle in the elderly. J Appl Physiol 115:812-818
7. Rutten EP, Spruit MA, Wouters EF (2009) Critical view on diagnosing muscle wasting by single-frequency bio-electrical impedance in COPD. Respir Med 104:91-98

8. Trutschnigg B, Kilgour RD, Reinglas J et al (2008) Precision and reliability of strength (Jamar vs Biodex handgrip) and body composition (dual-energy X-ray absorptiometry vs bioimpedance analysis) measurements in advanced cancer patients. Appl Physiol Nutr Metab 33:1232-1239

9. Yamada Y, Schoeller DA, Nakamura E et al (2010) Extracellular water may mask actual muscle atrophy during aging. J Gerontol A Biol Sci Med Sci 65:510-516

10. Yamada Y, Matsuda K, Björkman MP et al (2014) Application of segmental bioelectrical impedance spectroscopy to the assessment of skeletal muscle cell mass in elderly men. Geriatr Gerontol Int 14:129-134

11. Yamada Y, Buehring B, Krueger D et al (2017) Electrical properties assessed by bioelectrical impedance spectroscopy as biomarkers of age-related loss of skeletal muscle quantity and quality. $\mathbf{J}$ Gerontol A Biol Sci Med Sci 172:1180-1186

12. Björkman MP, Finne-Soveri H, Pilvi TK et al (2012) Bioimpedance spectroscopy as a measure of physical functioning in nursing home residents. Aging Clin Exp Res 24:612-618

13. Bjorkman MP, Suominen MH, Pitkälä KH et al (2013) Porvoo sarcopenia and nutrition trial: effects of protein supplementation on functional performance in home-dwelling sarcopenic older people - study protocol for a randomized controlled trial. Trials 14:387. https://doi.org/10.1186/1745-6215-14-387

14. Folstein MF, Folstein SE, McHugh PR (1975) "Mini-mental state": a practical method for grading the cognitive state of patients for the clinician. J Psychiatr Res 12:189-198

15. Hays RD, Sherbourne CD (1993) Mazel RM (1993) The RAND 36-item health survey 1.0. Health Econ 2:217-227

16. Aalto A-M, Aro AR, Teperi J. RAND-36 Terveyteen liittyvän elämänlaadun mittarina-Mittarin luotettavuus ja suomalaiset väestöarvot, Stakes Sosiaali- ja terveysalan tutkimus- ja kehittämiskeskus 1999; Tutkimuksia / Stakes = Research reports / National Research and Development Centre for Welfare and Health : 101. (in Finnish). http://urn.fi/URN:NBN:fi-fe20121108 9642

17. Charlson ME, Pompei P, Ales KL et al (1987) A new method of classifying prognostic comorbidity in longitudinal studies: development and validation. J Chronic Dis 40:373-383

18. Rikli RE, Jones CJ (2013) Development and validation of criterion-referenced clinically relevant fitness standards for maintaining physical independence in later years. Gerontologist 53:255-267

19. Guralnik JM, Simonsick EM, Ferrucci L et al (1994) A short physical performance battery assessing lower extremity function: association with self-reported disability and prediction of mortality and nursing home admission. J Gerontol 49:M85-94

20. Yamada Y, Yoshida T, Yokoyama K et al (2017) Kyoto-Kameoka Study. The extracellular to intracellular water ratio in upper legs is negatively associated with skeletal muscle strength and gait speed in older people. J Gerontol A Biol Sci Med Sci 72:293-298

Publisher's Note Springer Nature remains neutral with regard to jurisdictional claims in published maps and institutional affiliations. 